\title{
Tunnelling in the Urban Environment
}


Other titles from previous Géotechnique Symposium in Print events:

Geotechnical Earthquake Engineering (Géotechnique Symposium in Print). (2015) S. Haigh (ed.). ISBN 978-0-7277-6149-1

Bio- and Chemo- Mechanical Processes in Geotechnical Engineering

(Géotechnique Symposium in Print). (2013)

L. Laloui (ed.). ISBN 978-0-7277-6053-1

Partial Saturation in Compacted Soils (Géotechnique Symposium in Print) (2011)

D. Gallipoli (ed.). ISBN 978-0-7277-5775-3 


\section{Tunnelling in the Urban Environment}

Géotechnique Symposium in Print 2017

Edited by

Lidija Zdravković

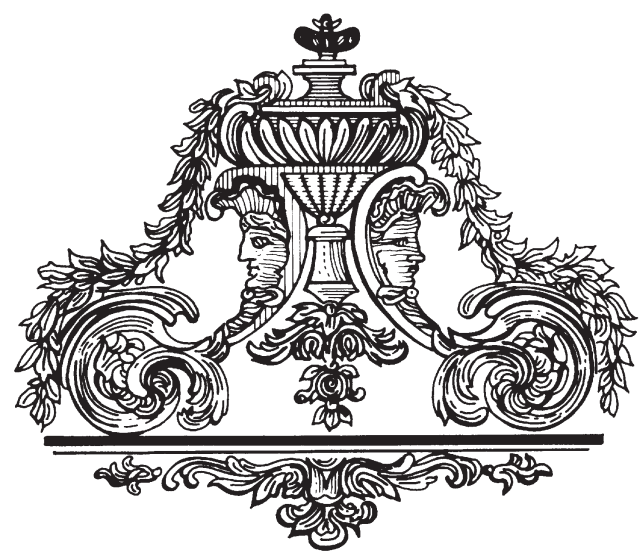


Published by ICE Publishing, One Great George Street, Westminster, London SW1P 3AA.

Full details of ICE Publishing representatives and distributors can be found at: www.icebookshop.com/bookshop_contact.asp

\section{Other titles by ICE Publishing:}

Civil Excavations and Tunnelling: A practical guide, Second edition

Ratan Tatiya. ISBN 978-0-7277-6153-8

Handbook of Tunnel Fire Safety, Second edition

Alan Beard and Richard Carvel. ISBN 978-0-7277-4153-0

Specification for Tunnelling, Third edition

British Tunnelling Society (BTS), Institution of Civil Engineers (ICE) and

Michael Francis. ISBN 978-0-7277-3477-8

www.icebookshop.com

A catalogue record for this book is available from the British Library

ISBN 978-0-7277-6377-8

(C) Thomas Telford Limited 2018

ICE Publishing is a division of Thomas Telford Ltd, a wholly-owned subsidiary of the Institution of Civil Engineers (ICE).

All rights, including translation, reserved. Except as permitted by the Copyright, Designs and Patents Act 1988, no part of this publication may be reproduced, stored in a retrieval system or transmitted in any form or by any means, electronic, mechanical, photocopying or otherwise, without the prior written permission of the Publisher, ICE Publishing, One Great George Street, Westminster, London SW1P 3AA.

This book is published on the understanding that the author is solely responsible for the statements made and opinions expressed in it and that its publication does not necessarily imply that such statements and/or opinions are or reflect the views or opinions of the publishers. While every effort has been made to ensure that the statements made and the opinions expressed in this publication provide a safe and accurate guide, no liability or responsibility can be accepted in this respect by the author or publishers.

While every reasonable effort has been undertaken by the author and the publisher to acknowledge copyright on material reproduced, if there has been an oversight please contact the publisher and we will endeavour to correct this upon a reprint.

Commissioning Editor: James Hobbs

Production Editor: Madhubanti Bhattacharyya

Market Development Executive: Elizabeth Hobson

Typeset by The Manila Typesetting Company

Printed and bound in Great Britain by TJ International, Padstow 


\section{Preface}

The response of the ground and nearby structures and services to tunnelling constitutes a complex soil-structure interaction boundary value problem. The conditions around tunnels will depend on the stress state in the ground, soil type, tunnel geometry, construction technique and permeability of the tunnel lining with respect to that of the ground. The complexity of tunnelling conditions increases further when considering a typical urban environment, with buildings above where tunnels are to be constructed, or other tunnels and services crossing above or below the new tunnel construction. For this reason, physical modelling and monitoring of full-scale tunnels are frequently employed to gain insight into mechanisms of deformation and failure of tunnels. More often, with an increasingly congested underground space, sophisticated numerical analyses are the principal means of understanding detailed mechanisms of multiple soil-structure interactions.

With urban tunnel construction growing worldwide, being able to predict accurately the ground and structural response to tunnelling and the associated risks is crucial. This is fundamental to safeguarding the urban fabric, such as existing infrastructure for transport and services and historic and sensitive structures. Even though it faces many engineering challenges, tunnelling design has seen significant advances, both practically and academically, over the past 20 years. In the UK alone, major projects, like the Jubilee Line Extension, Channel Tunnel Rail Link and most recently Crossrail, have left an invaluable legacy of new knowledge, innovation and practical experience in tunnel construction, with many new projects poised to benefit from this legacy.

As a leading geotechnical journal, Géotechnique has regularly published papers on tunnelling, from its inception to the present day. It was therefore very timely for the journal to host a symposium in print on this topic. The response to the call for abstracts was considerable. Following the standard Géotechnique review process, six papers were selected for publication in the dedicated symposium issue of Géotechnique, while five others appeared in subsequent general Géotechnique issues. The papers group into four topics, from greenfield tunnelling to effects of tunnelling on surface structures, on existing tunnels and on pile foundations. Moreover, studies within each topic explore the engineering challenges with different tools, including field monitoring, physical modelling and numerical analysis. The list of the investigated case studies comprises the Channel Tunnel Rail Link and Crossrail in the UK and the Barcelona metro construction in Spain. Additionally, one of the selected papers addresses design aspects of sprayed concrete lined tunnels in relation to the Eurocode 7 design code, and how this can be used in conjunction with numerical analysis.

The special issue of Géotechnique was supplemented by the symposium in print event on 14 September 2017 at the Institution of Civil Engineers, also supported by the British Tunnelling Association. This was a whole-day event, organised in two sessions, with presentations of all selected papers and ample time available for discussion.

As a Symposium chair, I enjoyed immensely working with colleagues on the symposium sub-committee, who contributed significant effort in assessing papers over a tight time scale, making the special Géotechnique issue and the event possible. We thank numerous external reviewers for their prompt and constructive responses. Final thanks are due to Craig Schaper, Journals Editor at ICE Publishing, for his efforts and advice during this process, and to Ben Ramster, Journals Manager at ICE Publishing, for his help and support at the Symposium event.

\section{Symposium in print sub-committee chairman}

Professor Lidija Zdravković, Imperial College London, UK

\section{Symposium in print sub-committee members}

Dr David Chapman, University of Birmingham, UK

Dr Mohammed Elshafie, Cambridge University, UK

Dr Paul Morrison, Arup, UK

Professor Helmut Schweiger, Graz University of Technology, Austria

Dr Jamie Standing, Imperial College London, UK

Professor Giulia Viggiani, University of Rome Tor Vergata, Italy 
Downloaded by [] on [26/04/23]. Copyright $\odot$ ICE Publishing, all rights reserved. 


\section{Session 1}

\section{Session A. Greenfield tunnelling}

Measured short-term subsurface ground displacements from EPBM tunnelling in London Clay M. S. P. Wan, J. R. Standing, D. M. Potts and J. B. Burland

Twin-tunnelling-induced changes to clay stiffness S. Divall, R. J. Goodey and S. E. Stallebrass

\section{Session B. Interaction of tunnelling and surface structures}

Protecting sensitive constructions from the impact of tunnelling: the case of World Heritage buildings in Barcelona

A. Ledesma and E. E. Alonso

Finite-element modelling for the assessment of tunnel-induced damage to a masonry building W. N. Yiu, H. J. Burd and C. M. Martin

Influence of building characteristics on tunnelling-induced ground movements

S. Ritter, G. Giardina, M. J. Dejong and R. J. Mair

\section{Session 2}

Session C. Effect of tunnelling on existing tunnels

Numerical investigation of the effects of tunnelling on existing tunnels

V. Avgerinos, D. M. Potts and J. R. Standing

Tunnelling close beneath an existing tunnel in clay - perpendicular undercrossing

C. Y. Gue, M. J. Wilcock, M. M. Alhaddad, M. Z. E. B. Elshafie, K. Soga and R. J. Mair

Session D. Effect of tunnelling on pile foundations

Response of full-scale piles to EPBM tunnelling in London Clay

D. Selemetas and J. R. Standing

Open-face tunnelling effects on non-displacement piles in clay - part 1: centrifuge modelling techniques

M. G. Williamson, M. Z. E. B. Elshafie, R. J. Mair and M. D. Devriendt

Open-face tunnelling effects on non-displacement piles in clay-part 2: tunnelling beneath loaded piles and analytical modelling M. G. Williamson, R. J. Mair, M. D. Devriendt and M. Z. E. B. Elshafie

Session E. Design codes and tunnelling

Eurocode 7-based design of SCL tunnels by means of numerical analyses 